\section{Programa de Pós-Graduação em Educação Física da Universidade São Judas Tadeu-SP}

\section{Physical Education Post-Graduation Programme at Universidade São Judas Tadeu-SP}

Maria Luiza de Jesus Miranda ${ }^{1}$

Alexander Barreiros Cardoso Bomfim ${ }^{2}$

Sheila Aparecida Pereira dos Santos Silva ${ }^{1}$

\section{Resumo}

Este artigo tem como objetivo apresentar o Programa de Pós Graduação em Educação Física da Universidade São Judas Tadeu, relatando as circunstâncias da criação dos cursos de Mestrado em 2004 e de Doutorado em 2010. Para isso serão descritos o objetivo do programa, sua estrutura curricular, o corpo docente e a forma de ingresso discente, bem como as ações para implementar a produção científica docente e discente, as dificuldades enfrentadas no seu desenvolvimento, finalizando com uma visão prospectiva face à orientação da Capes para a Área 21.

\section{Palavras-chave}

Educação Física; Pós Graduação; Mestrado; Doutorado.

\begin{abstract}
The objective of this paper is to present the Physical Education Post-Graduation Programme from the University São Judas Tadeu, reporting the circumstances of the Master and Doctorate's courses creation, in 2004 and 2010 respectively. In order to do this there will be a description of the objective of the programme; its curricular structure; the academic teaching staff and how the students are selected; as well as the actions to implement the scientific production both from the academic teaching staff and students; the major issues the Programme dealt with in its development, finishing off by looking ahead as regards to the orientation of Capes for Area21.
\end{abstract}

\section{Keywords}

Physical Education; Post Graduation; Master; Doctorate.
Rev Bras Ativ Fis Saúde p. 341-346 DOI: http://dx.doi.org/10.12820/2317. $1634.2012 \mathrm{v} 17 \mathrm{n} 5 \mathrm{p} 341$

1 Programas de Pós Graduação em Educação Física, Universidade São Judas Tadeu, São Paulo, SP, Brasil.

2 GEPEMH - Grupo de Estudo em Motricidade Humana 


\section{INTRODUÇÃO}

A Universidade São Judas Tadeu (USJT), criada há 41 anos para integrar o Complexo Educacional São Judas Tadeu iniciado em 1947, oferece 30 cursos de graduação e nove cursos de formação específica nas mais variadas áreas do conhecimento, além de 02 cursos superiores de tecnologia, e funciona em duas Unidades: Butantã e Mooca. Somente na Unidade Mooca, com aproximadamente 80 mil metros quadrados de área, convivem cerca de 20 mil alunos, 610 professores e 490 funcionários.

Embora com tradição na Graduação, cuja maioria dos cursos obtêm conceito 4 ou superiores nas avaliações do MEC/INEP, a produção de conhecimento sempre esteve entre os objetivos da USJT. Isso se faz notar na criação do Centro de Pesquisa, na implantação de um Regime de Iniciação Científica diferenciado e de Núcleos de Pesquisa em diferentes áreas do conhecimento, constituindo o caminho para a Pós Graduação. Atualmente a Universidade conta com 29 cursos de especialização Lato Sensu e quatro programas Stricto Sensu reconhecidos pela Capes: Filosofia (2002); Educação Física (2003); Arquitetura e Urbanismo (2004); e Ciências do Envelhecimento (2009).

Este artigo tem como objetivo apresentar o Programa de Pós Graduação em Educação Física (PGEDF) da Universidade São Judas Tadeu, destacando seu objetivo, a estrutura curricular, o corpo docente e os principais elementos do desenvolvimento por meio de informações levantadas na Coordenação do Programa, tendo como fonte principal o Coleta Capes.

\section{BREVE HISTÓRICO}

O Programa de Pós Graduação em Educação Física (PGDEF) da USJT originou-se de Núcleo de Pesquisa específico da área de Educação Física, constituído na USJT no início de 2001. Esse Núcleo era formado por vários grupos de estudo de diferentes linhas temáticas, e cadastrados no Diretório de grupos de pesquisa do $\mathrm{CNPq}$ com projetos de pesquisa posteriormente publicados como artigos ou capítulos de livros.

Assim, a criação do projeto de Programa de Pós Graduação, consoante aos critérios de qualidade exigidos pela Capes, foi decorrência da união de interesses de professores da Universidade, que tinham como meta produzir conhecimentos para a área, com os de uma instituição que se propunha a oferecer condições adequadas para o desenvolvimento desse projeto.

O PGEDF ofereceu, primeiramente, o curso de Mestrado que, recomendado pelo Conselho Técnico Científico (CTC) da CAPES em dezembro de 2003, deu início à $1^{\text {a }}$ turma em fevereiro de 2004. Naquele momento, existiam apenas 11 programas de Pós Graduação em Educação Física no País, sendo quatro no Estado de SP, dois em SC e um nos Estados do RJ, RS, MG, PR, DF, sendo o PGEDF-USJT o quarto a ser criado em instituição privada no país, e o segundo no Estado de São Paulo. Nas 1a e 2a Avaliações Trienais (2004/2005/2006 e 2007/2008/2009) o Programa obteve Conceito 4, como resultado do atendimento das orientações da Capes. A qualidade do Mestrado ficou evidente quando o CTC, em sua 114a reunião, recomendou o curso de Doutorado, em dezembro de 2009. Deste modo, a USJT foi a primeira instituição particular do Estado de São Paulo a oferecer, em seu Programa de Pós-Graduação Stricto Sensu em Educação Física, os dois níveis de formação: Mestrado e Doutorado. 


\section{OBJETIVO DO PGEDF-USJT}

O objetivo do PGEDF é formar pesquisadores na área e qualificar docentes para o nível superior, especializados no estudo da motricidade humana, por meio de um aprofundamento dos conhecimentos específicos em Educação Física, bem como de outras áreas que permeiam seu desenvolvimento. Dessa maneira, vislumbra-se a possibilidade de contribuir para a formação de melhores professores universitários, além de ampliar a produção científica em Educação Física. Isso tem sido demonstrado a partir dos resultados obtidos por egressos do programa: dos 126 mestres e 4 doutores titulados até junho de 2012, 57 conseguiram aprovação em concursos públicos e privados para docência em Instituições de Ensino Superior de vários estados brasileiros, e mais 6 deles para cargos de coordenação de curso.

\section{ESTRUTURA ORGANIZACIONAL DO PGEDF-USJT}

Tendo como Área Básica: Educação Física e Área de Concentração: "Escola, Esporte, Atividade Física e Saúde”, o programa contempla estudos metodológicos, pedagógicos, biodinâmicos e psicossociais, manifestos na prática da Educação Física e do Esporte, em diferentes âmbitos de aplicação, na perspectiva da qualidade de vida.

Os projetos e estudos estão distribuídos em quatro Linhas de Pesquisa (LP):

\section{- LP1: Atividade Física e Disfunções Orgânicas}

Estuda a associação entre atividade física e as disfunções orgânicas nos aspectos morfológicos, fisiológicos, nutricionais, psicológicos e biomecânicos, em modelos experimentais e em diferentes populações. Investiga, ainda, as interações entre essas disfunções e o controle da postura e do movimento humano.

- LP2: Educação Física, Escola e Sociedade

Reúne estudos históricos, sociais, políticos e pedagógicos dos condicionantes da Educação Física nos contextos escolar e não escolar, a partir de metodologias das ciências biológicas e humanas. Além disto, a linha abarca aspectos relativos à formação e atuação profissional.

- LP3: Fenômeno Esportivo

Tem como foco os estudos sobre o fenômeno "Esporte" em diferentes dimensões: educacional, de lazer, e de alto rendimento, analisado nas perspectivas sociais, pedagógicas, psicológicas e biodinâmicas.

- LP4: Promoção e Prevenção em Saúde

Estuda a aplicação dos constructos básicos da Promoção da Saúde na perspectiva da Educação Física, bem como desenvolve pesquisa relacionada à atividade física na Prevenção em Saúde em vários níveis: fisiológico, morfológico, metabólico, perceptivo. Estuda, ainda, os resultados da participação de diferentes populações em programas de Educação Física/atividade física quanto aos aspectos antropológicos, biológicos, psicossociais, educacionais, sensoriais e motores.

O corpo docente acredita que seja relevante, para manter a especificidade da Área da Educação Física, a presença de linha de Pesquisa e projetos focalizando a área Pedagógica, seguindo abordagens das Ciências Humanas e Sociais. Para tanto, o programa vê como prioritária a manutenção de docentes e busca a ampliação da produção específica qualificada nessa área. 
O Corpo Docente atual é formado por 12 professores permanentes e dois colaboradores, cuja vinculação às linhas de pesquisa consta no Quadro 1 juntamente com a quantidade de Grupos de Pesquisa liderados por eles e cadastrados no CNPq.

Quadro 1 - Docentes e Grupos de Pesquisa por Linha de Pesquisa

\begin{tabular}{|lll|}
\hline \multicolumn{1}{|c|}{ Linha de Pesquisa } & Docente & Categoria \\
\hline \multirow{3}{*}{ Atividade Física e Disfunções Orgânicas } & Bruno Rodrigues & Permanente \\
07 Grupos de Pesquisa & Claudia Borim da Silva Eliane & Colaborador \\
& Laura Maifrino & Permanente \\
& Romeu R. Souza & Permanente \\
& Ulysses Ervilha & Permanente \\
\hline \multirow{3}{*}{ Educação Física, Escola e Sociedade } & Cássio de Miranda Meira Jr. & Permanente \\
02 Grupos de Pesquisa & Elisabete dos Santos Freire & Permanente \\
& Graciele Massoli Rodrigues & Permanenter \\
& Maria Luiza J. Miranda & Permanente \\
& Sheila Ap. P.Santos Silva & Permanente \\
\hline \multirow{3}{*}{ Fenômeno Esportivo } & Cássio de Miranda Meira Jr. & Colaborador \\
02 Grupos de Pesquisa & Claudia Borim da Silva & Colaborador \\
& Graciele Massoli Rodrigues & Permanente \\
& Maria Regina Brandão & Permanente \\
& Sheila Ap. P.Santos Silva & Permanente \\
& Ulysses Ervilha & Permanente \\
\hline Promoção e Prevenção em Saúde & Aylton Figueira Jr. & Permanente \\
& Bruno Rodrigues & Permanente \\
& Claudia Borim da Silva & Colaborador \\
& Eliane Florêncio Gama & Permanente \\
& Érico Chagas Caperuto & Permanente \\
& Maria Luiza J. Miranda & Permanente \\
\hline
\end{tabular}

Esses grupos desenvolvem seus estudos nos seguintes laboratórios: Laboratório de Pedagogia do Movimento Humano, Laboratório de Percepção Corporal e Movimento, Laboratório do Movimento Humano, Laboratório de Fisiologia Experimental, Laboratório de Estudos Morfoquantitativos e Imunohistoquímicos, Laboratório de Biomecânica.

\section{PROCESSO SELETIVO}

Anualmente são disponibilizadas 25 vagas para o curso de Mestrado e 10 para o Doutorado com processos seletivos diferenciados. Para o Mestrado, há quatro etapas: prova escrita, análise de projetos de pesquisa e entrevista, todas com caráter eliminatório; e análise do currículo Lattes, com caráter classificatório. Para o Doutorado, são três etapas, não havendo prova escrita. As diretrizes para o processo seletivo são estabelecidas em edital divulgado por meio da página do programa na internet (http://www.usjt.br/pgedf/).

A distribuição dos candidatos inscritos, aprovados/matriculados e titulados nos processos seletivos de Mestrado e Doutorado ao longo dos anos consta na Tabela 1:

O PGEDF recebe candidatos de vários lugares do Brasil, oriundos de Universidades públicas e privadas, professores universitários e profissionais recém-formados, além de um grande número de integrantes dos grupos de estudo e pesquisa da própria USJT. 
Tabela 1 - Distribuição dos candidatos e aprovados nos processos seletivos

\begin{tabular}{|c|c|c|c|c|c|c|}
\hline Ano & Candidatos $M$ & Matriculados M & Titulados M & Candidatos D & Matriculados D & Titulados D \\
\hline 2004 & 58 & 15 & 15 & & & \\
\hline 2005 & 58 & 20 & 18 & & & \\
\hline 2006 & 50 & 20 & 19 & & & \\
\hline 2007 & 43 & 19 & 18 & & & \\
\hline 2008 & 53 & 19 & 18 & & & \\
\hline 2009 & 53 & 20 & 17 & & & \\
\hline 2010 & 57 & 15 & 14 & 22 & 12 & \\
\hline 2011 & 48 & 16 & & 23 & 12 & 2 \\
\hline 2012 & 30 & 12 & & 24 & 9 & 2 \\
\hline
\end{tabular}

\section{AÇÕES VISANDO À AMPLIAÇÃO DA PRODUÇÃO CIENTÍFICA}

As metas do Programa são estabelecidas pelo Colegiado de Curso, que procuram se manter fiéis aos propósitos declarados na criação do Programa e , além disso, atender às orientações da Coordenação, que informa o grupo a respeito das diretrizes emanadas da CAPES/Área 21. Tais metas orientam ações docentes, discentes e direcionam a interlocução necessária entre o Programa e demais instâncias da USJT. Houve uma melhora significativa de produção nos últimos anos, passando de 76 artigos produzidos no $1^{\circ}$ triênio de existência do Programa, para 138 no segundo triênio, com 11 e 12 docentes, respectivamente. Em setembro de 2012, o Programa já conta com 114 artigos publicados, além de 15 artigos, três livros e seies capítulos de livros aprovados para publicação. O diferencial no presente triênio é a tendência de predominância de publicação nos estratos superiores do Qualis. Mesmo quando a participação em eventos científicos específicos não é pontuada pela Área 21, os docentes e discentes têm investido nisso com o objetivo de divulgar os resultados de suas investigações e ampliar a visibilidade do Programa.

Dentre as ações empreendidas no sentido de ampliar a produção científica de docentes e discentes, se mostrou muito acertada a decisão do Colegiado de aumentar a exigência na publicação de artigo relacionado aos trabalhos de Dissertação ou Tese. As defesas dos mestrandos só podem ocorrer após a submissão de artigo a periódico qualificado, ou o aceite do artigo no caso dos doutorandos.

O PGEDF tem procurado, ainda, ampliar as colaborações e vínculos de pesquisa com outras Instituições e pesquisadores, tanto nacionais quanto internacionais. Já há parcerias estabelecidas com as universidades de Alborg, na Dinamarca; Técnica de Lisboa, em Portugal; Cauca, na Colômbia; bem como com a UNIFESP, USP, UNICAMP, entre outras.

\section{DESENVOLVIMENTO DO PGEDF-USJT FACE À ORIENTA- ÇÃO DA CAPES PARA A ÁREA 21}

Procedimentos voltados ao crescimento e evolução do PGEDF constam num plano de ações. Esse plano visa ao aumento das publicações docentes e discentes, mantendo a qualidade dessa produção, para consolidar o conceito do curso e, futuramente, alcançar um conceito mais alto. A produção do Programa, gradativamente, passa a ser veiculada internacionalmente, e tanto os docentes, quanto os discentes que 
ainda não possuem essa prática, vêm sendo estimulados a isso, contando, inclusive, com apoio institucional para a elaboração da versão em inglês de seus trabalhos.

Outro aspecto previsto no plano de ações é a elaboração de projetos temáticos, envolvendo vários professores das Linhas de Pesquisa do Programa. O eixo norteador do primeiro projeto temático é dado pelo Projeto Sênior para a Vida Ativa, coordenado pelas Profas Dras Maria Luiza J. Miranda e Ana Martha Limongelli. Nele há estudos dos aspectos fisiológicos, bioquímicos, nutricionais, psicológicos e pedagógicos dos idosos participantes desse programa de extensão da USJT e estão envolvidos docentes do PGEDF e do Programa em Ciências do Envelhecimento. O Projeto-TEEN, relacionado a aspectos da adolescência, tem como pesquisador principal o Dr. Aylton Figueira Jr. Além de ter grande abrangência social, diagnosticará as características de saúde, estilo de vida e fatores de risco em adolescentes no Estado de São Paulo, oferecendo muitas oportunidades de assessoria à comunidade por meio dos seus diferentes estudos vinculados. Possibilitará, ainda, a geração de inúmeras publicações oriundas de trabalhos de Iniciação Científica e de conclusão de cursos de Graduação, Mestrado e Doutorado.

Continua sendo objetivo do Programa a busca de apoio para as pesquisas por meio de concorrência em editais de diferentes órgãos. Apesar das dificuldades e restrições postas às Instituições Privadas, projetos têm sido enviados constantemente às agências de fomento e alguns já foram aprovados nas temáticas de Formação Profissional e de Fisiologia do Exercício.

O corpo docente permanente do programa conta com o apoio financeiro dos órgãos de fomento e da própria USJT para a participação em eventos científicos, tanto internacionais quanto nacionais. Esse movimento tem sido constante desde a implantação no triênio passado de verba específica para a saída de docentes. No ano de 2011, foram 12 as participações de docentes em eventos internacionais e 37 em eventos nacionais que, somadas às dos anos anteriores, divulgaram a produção do Programa e a Instituição.

\section{CONSIDERAÇÕES FINAIS}

O PPGEDF-USJT está em constante evolução, consonante com a consolidação prevista nos anos anteriores. Os indicadores relativos às Dissertações e Teses defendidas, bolsas e auxílios obtidos nos órgãos de fomento e na própria USJT, o apoio institucional às publicações e saídas dos docentes para eventos, à produção crescente, apenas para citar alguns dos pontos relevantes, demonstram essa evolução.

O comprometimento de todo o corpo docente com o rigor nos procedimentos e exigências imprescindíveis para a consolidação do Programa, bem como a busca por evolução contínua é outro aspecto muito positivo a ser considerado. Além das reuniões de colegiado, há o contato constante entre os docentes e entre estes e a coordenação no sentido de identificar as necessidades e soluções para o bom andamento dos trabalhos e a superação de obstáculos. Essa sistemática contribui para que o Programa apresente um desenvolvimento equivalente ao de instituições públicas renomadas e bem avaliadas

Endereço para Correspondência

Maria Luiza de Jesus Miranda R. Taquari, 546 Mooca, São Paulo CEP 03166-000 prof.mlmiranda@usjt.br Telefone 011-2799-1917
Recebido 04/09/2012 Revisado 03/11/2012 Aprovado 20/11/2012 